\title{
Can thyroid stimulating hormone levels by TSH (IRMA) predict relapse of thyrotoxicosis following carbimazole treatment?
}

\author{
R. Wilson, C.G. Semple, A.M. Reid ${ }^{1}$, A.C.A. Glen ${ }^{1}$, J.H. McKillop and J.A. \\ Thomson
}

University Department of Medicine, Royal Infirmary, Glasgow G31 2ER and ${ }^{1}$ Department of Biochemistry, Victoria Infirmary, Glasgow, $U K$.

\begin{abstract}
Summary: Serum thyrotrophin receptor antibody (TRAb) and thyroid stimulating hormone (TSH) (IRMA) levels were measured in 38 patients at one month after the end of a course of carbimazole/ $\mathbf{T}_{3}$ therapy for Graves' disease. Despite the increased sensitivity of the IRMA assay a TSH measurement at this stage was found to be of no predictive value, in contrast to estimation of serum TRAb levels which correctly predicted relapse and remission in $90 \%$ of patients.
\end{abstract}

\section{Introduction}

Following treatment of Graves' disease with antithyroid drugs, some patients will enter remission while others relapse. Previous studies ${ }^{1,2}$ have assessed the value of thyrotrophin receptor antibodies (TRAb) in identifying patients likely to relapse. These have met with varying degrees of success. While in our experience an elevated TRAb index was associated with relapse ${ }^{2}$ this test is time consuming and is not routinely used in the majority of laboratories. Dahlberg et al. $^{3}$ claimed that a normal thyroid stimulating hormone (TSH) response to a thyrotrophin releasing hormone (TRH) test was a useful indicator of remission. As it has been suggested ${ }^{4}$ that sensitive TSH measurements can replace the TRH test we decided to assess the ability of thyroid stimulating hormone (TSH) levels, estimated using a recently developed commercial immunoradiometric assay (IRMA) to indicate potential relapse and remission after carbimazole treatment of Graves' disease.

\section{Material}

The study group comprised 38 patients with clinically and biochemically diagnosed Graves' disease. These patients were treated for 12 months as follows; $0-1$ month $45 \mathrm{mg} /$ day of carbimazole, $1-2$ months $30 \mathrm{mg} /$ day of carbimazole, 2-12 months $20 \mathrm{mg} /$ day of carbimazole plus $60-80 \mu \mathrm{g}$ of triiodothyronine $\left(\mathrm{T}_{3}\right)$. The

Correspondence: R. Wilson, Ph.D.

Accepted: 9 April 1987. patients were followed for a minimum of 12 months after treatment. Samples for TSH estimation were obtained 1 month after the end of treatment to avoid the suppressive effect of $T_{3}$ on TSH Levels. TSH (IRMA) levels were measured using the Sucrosep assay system (Boots Celltech) in which within and between assay coefficients of variation were $1.5 \%$ at $20 \mathrm{mU} / 1,4 \%$ at $2 \mathrm{mU} / 1$ and $10 \%$ at $0.3 \mathrm{mU} / \mathrm{l}$. The levels of TSH (IRMA) in euthyroid controls ranged from 0.3 to $6.0 \mathrm{mU} / 1$. TRAb levels were measured as described previously ${ }^{2}$ at the end of carbimazole $/ \mathrm{T}_{3}$ treatment.

\section{Statistics}

Results are expressed as mean \pm s.d. Data was analysed using a Wilcoxon Rank test.

\section{Results}

Thirteen of 38 patients relapsed within the first year. The results (Figure 1) showed 9/38 patients to have undetectable TSH (IRMA) values. Of these, 3 relapsed and 6 remained in remission. Of the 29 patients with detectable TSH (IRMA) values 10 relapsed and 19 remained in remission. There was no significant difference in mean TSH IRMA levels between those who relapsed and those who remained in remission (1.26 \pm 1.5 vs $1.8 \pm 2.5, P>0.1)$.

Twenty three of the 38 patients had TSH levels less than $0.08 \mathrm{mU} / 1$ and of these 9 relapsed. This TSH level

(C) The Fellowship of Postgraduate Medicine, 1987 


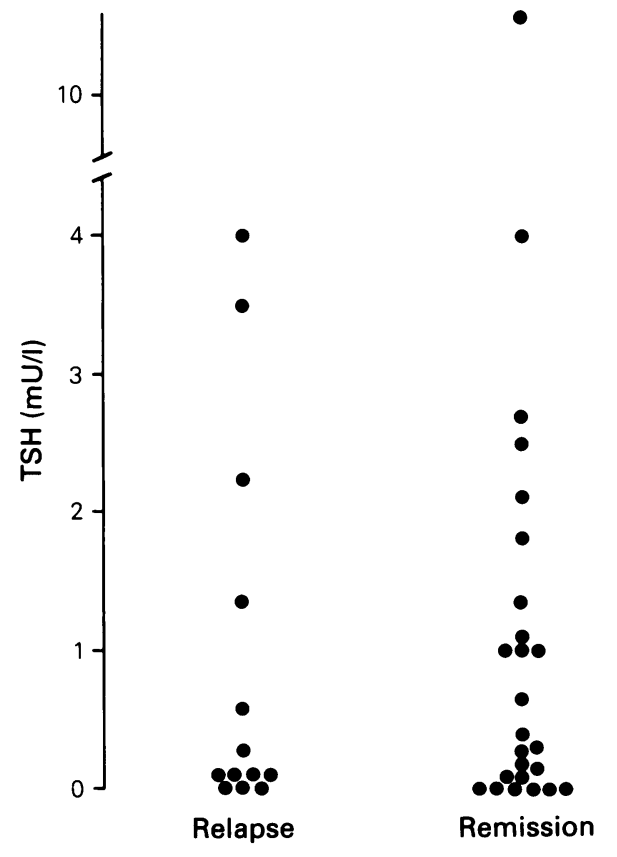

Figure 1 TSH levels at 1 month off carbimazole/ $\mathrm{T}_{3}$ therapy.

was selected as it has been suggested that patients with TSH (IRMA) levels less than $0.08 \mathrm{mU} / 1$ would not be expected to respond to a TRH test. ${ }^{5}$

Of the 13 patients who relapsed 11 had elevated

\section{References}

1. McGregor, A., Rees Smith, B., Hall, R., Peterson, M.M., Miller, M. \& Dewer, P.J. Predictor of relapse in hyperthyroid Graves' disease. Lancet 1980, i: 1101-1103.

2. Wilson, R., McKillop, J.M., Pearson, D.W.M., Cuthbert, G.F. \& Thomson, J.A. Relapse of Graves' disease after medical therapy: Predictive value of thyroidal-technetium $^{99 \mathrm{~m}}$ and thyroid stimulating hormone receptor antibody levels. $J$ Nucl Med, 1985, 26: 1024-1028.

3. Dahlberg, P.A., Karlsson, A., Jansson, R. \& Wide, L.
TRAb levels. Of the 25 who remained in remission 23 had TRAb levels within the normal range $(P<0.05)$.

\section{Discussion}

In an earlier study Dahlberg et al. ${ }^{3}$ investigated the prognostic value of a TRH test in thyrotoxicosis and found that $74 \%$ of patients who developed a normal TSH response to TRH during therapy would remain in remission compared to the $29 \%$ who did not. The authors, however, made no mention of whether basal TSH levels differed significantly between groups.

One of the main advantages of the sensitive TSH (IRMA) test is that the lower limit of the normal range can be defined and as a result patients with suppressed circulating levels of TSH can be distinguished. Therefore it might have been anticipated that patients likely to have a relapse of thyrotoxicosis after carbimazole treatment would have suppressed TSH levels measured by an IRMA assay. This small study has shown this not to be the case. All patients in this study received $T_{3}$ therapy. After 1 month off carbimazole/ $T_{3}$ TSH levels ranged from undetectable to $10.6 \mathrm{mU} / 1$. This makes it unlikely that TSH levels are suppressed by the previous $T_{3}$ treatment.

TRAb levels were measured in these patients following a 12 month course of antithyroid drugs and were found to predict cases of relapse and remission in $90^{\circ}$ of patients. This is in keeping with previous studies

The results from this study would suggest that TSI (IRMA) levels obtained at 1 month after the end of antithyroid drug therapy are of little use in identifying patients likely to relapse or remain in remission.

Thyrotrophin-releasing hormone testing during antithyroid drug treatment of Graves' disease as an indicator of remission. J Clin Endocrinol Metab 1985, 61: 1100-1109.

4. Caldwell, G., Gow, S.M., Sweeting, V.M. et al. A new strategy for thyroid function testing. Lancet 1985, 00: 1111-1119.

5. Kerr, D.J. \& Alexander, W.D. Is the TRH test usually unnecessary. Lancet 1984, ii: 1161-1162. 